\title{
Një regjistër osman i viteve 1845-1846 në Arkivin Osman të Stambollit dhe një statistikë e pajtimeve të gjaqeve në Toskëri
}

Ermal Nurja

Në periudhën klasike osmane (shek. XV deri në shpalljen e Tanzimatit në fillimet e shek. XIX), sigurimi i rendit dhe sigurisë në një kaza, ${ }^{1}$ ishte detyrë e sanxhakbeut të sanxhakut ${ }^{2}$ nga vareshin kazatë në fjalë. Kjo ishte detyrë e tij, pasi në llogarinë e tij shkonte edhe taksa e krimeve dhe vrasjeve [resm-i cürmü-cinayet (resm-i xhyrm ve xhinajet)] që mblidhej nga banorët e sanxhakut. Shtimi i akteve penale në një sanxhak mund të shkaktonte largimin e tij nga detyra prej sulltanit; në raste kur anarkia kthehej në një shqetësim të madh me pasoja, pra në raste ekstreme, edhe ekzekutimin e tij. Në raste vrasjesh, në gjyq paraqitej vojvoda i sanxhakbeut, i cili kërkonte nga gjyqi zbardhjen e akteve të vrasjeve apo plagosjeve të rënda dhe marrjen e një vendimi nga gjykatësi me këtë rast.

Pas shpalljesh së Tanzimatit, e gjithë administrata ushtarake, civile, fetare, financiare dhe ajo administrative kaluan një reformë të thellë sipas modelit francez. Si pjesë e kësaj reforme u parashikua edhe pajtimi i gjaqeve nëpër gjithë hapësirat e Perandorisë Osmane. Kjo politikë në Shqipëri do të vazhdonte deri në fund të sundimit osman, në vitin 1912.

Gjatë hulumtimeve në Arkivin Osman të Stambollit konstatova një shënim arkivor në një nga katalogët e arkivit që mbante titullin Çështjet në Gegëri. Regjistri në fjalë gjendej i katalogizuar nën referencën arkivore BEO, Ayn.d, No. 1716 (Fondi Porta e Lartë, pra Qeveria Osmane). Në të vërtetë fleta e prerë në formë të rrumbullakët dhe e ngjitur nga arkivistët osmanë (që

1 Ndarje administrative e ngjashme me nën-prefekturën.

2 Ndarje administrative e ngjashme me prefekturën. 


\section{Albanon}

Revistë kulturore

në shekullin XIX, kur u krye edhe katalogimi i parë i dokumentacionit) shkruan Gegëri (Gegalık-Gegallëk), madje me këtë titull është hartuar edhe regjistri, por nga leximi i tekstit rezulton se ai ka të bëjë me Toskërinë, jo me Gegërinë.

Data ekstreme, kur janë hartuar procesverbalet e pajtimeve janë vitet 18451846.

Regjistri i pajtimeve për Toskërinë përmban 193 faqe (99 fletë). Leximi i akteve vërteton se ato në të shumtën e rasteve janë regjistruar nga dy herë, diku fjalë-fjalë, diku duke lëvizur me radhën e tyre, diku duke u përzier edhe me akte që regjistrohen për herë të parë. Të shumtën e rasteve, aktet janë regjistruar nën emrin e kazasë (Vlora, Tepelena etj.) që është shkruar me bojë të kuqe. Kazatë e përfshira në regjistër janë si më poshtë:

Vlora fl. 1-21 (79 akte), fl. 93-102 (40 akte, gjysma e të cilave janë përsëritje); Berati me nahije: kazaja e Beratit fl. 21-40 (177 akte), fl. 57-74 (përsëritje), fl. 105-106 (6 akte), nahija Myzeqe fl. 41-42 (18 akte), fl. 74-76 (përsëritje), Skrapari fl. 43-50 (72 akte), fl. 76-84 (përsë ritje), Tomorrica fl. 50-54 (27 akte) fl. 84-88 (përsëritje);

Tepelena fl. 108-154 (230 akte), Tepelena-Vlora fl. 54/1-57 (19 akte), Kolonja fl. 102 (1 akt), Korça fl. 103 (2 akte), Janina fl. 103 (2 akte), nahija Pogon e Vlorës fl. 104 (5 akte), Përmeti fl. 106-108 (9 akte);

Konica fl. 88-92 (20 akte);

Delvina fl. 155-184 (279), fl. 184-192 (176 akte vrasjesh përsëritje dhe rregulluar në një format të ri), fl. 193 (akte zyrtare).

Shkresat zyrtare janë Vlora (fl. 1/1,2; 14/4; 21/2; 56/4,5; 57/1), Berat (fl. 54/1,2) dhe fl. 193.

Në një dokument nga një dëshmi e lëshuar nga banorët, mësohet se kush ishte personi, i cili është marrë me detyrën e gjyqeve të pajtimit, i emëruar me ferman të sulltanit. Ai quhej Haxhi Hyseni dhe për momentin kjo është e dhëna e vetme që ka të bëjë me identifikimin e tij.

Një tjetër veçori që bie në sy është fakti që regjistruesi i ka regjistruar nga dy herë në vende të ndryshme të regjistrit aktet e pajtimeve. Kështu ka ndodhur me aktet e Beratit (të gjitha aktet janë regjistruar nga dy herë), Delvinës, Myzeqesë, Skraparit, Tepelenës, Tomorricës dhe Vlorës (vetëm 20 akte janë regjistruar nga dy herë). 
Ndonëse në dokumentet zyrtare përmenden tri kaza si zona ku janë mbajtur gjyqet e pajtimit, më saktë: Vlora, Tepelena dhe Konica, në regjistër janë shënuar në kapituj më vete edhe Berati me nahijet e tij: Mallakstra, Skrapari dhe Tomorrica, Delvina. Nënkapitujt si Kolonja, Korça, Janina janë me pak akte dhe nën varësinë e kapitullit të Tepelenës, pra nuk kanë të bëjnë me kazanë në vetvete, por me banorë të këtyre kazave që kanë pasur konflikte të ndryshme me banorë të kazasë së Tepelenës.

Pjesa dërrmuese e konflikteve ka ndodhur mes banorëve të një kazaje, por nuk mungojnë edhe rastet mes banorëve të kazave të ndryshme, veçanërisht atyre të Tepelenës dhe Delvinës me banorë të kazave të tjera.

Koha e konflikteve shkon pas në kohë nga disa muaj deri në disa vite, maksimumi deri në 13 vite pas, megjithëse nuk mungojnë procesverbale që mëtojnë për kohë më të hershme siç ndodh në dy raste kur përmendet koha e rrethimit të Ali Pashë Tepelenës.

Përveç gjyqeve pajtuese për vrasjet, plagosjet dhe grabitjet që zënë pjesën dërrmuese të gjyqeve në regjistër janë regjistruar edhe mosmarrëveshje të tjera si ryshfet, zjarrvënie e qëllimshme, borxhe, xhizje, por përbëjnë një numër të vogël aktesh.

Nga përpunimi i të dhënave të regjistrit, më poshtë jepet edhe tabela ku janë treguar aktet e veprave penale që janë pajtuar në bazë të ligjit, sipas llojit, kazasë dhe numri përkatës për secilin prej tyre.

\begin{tabular}{|l|r|r|r|r|r|r|r|r|r|r|}
\hline Çështja penale & Berat & Delvinë & Myzeqe & Skrapar & Tepelenë & Tomorricë & Vlorë & Konicë & Total & $\%$ \\
\hline $\begin{array}{l}\text { Dokumente } \\
\text { zyrtare }\end{array}$ & 0 & 0 & 0 & 0 & 0 & 2 & 7 & 0 & 9 & 0,9 \\
\hline Ryshvet & 1 & 0 & 0 & 0 & 0 & 0 & 0 & 0 & 1 & 0,1 \\
\hline Zjarrvënie & 1 & 0 & 0 & 1 & 1 & 0 & 0 & 0 & 3 & 0,3 \\
\hline Borxhe & 1 & 1 & 1 & 0 & 7 & 0 & 0 & 0 & 10 & 1 \\
\hline Vrasje & 137 & 163 & 13 & 52 & 146 & 20 & 111 & 18 & 660 & 68,8 \\
\hline Plagosje & 29 & 13 & 1 & 5 & 28 & 4 & 0 & 0 & 80 & 8,4 \\
\hline Grabitje & 9 & 59 & 3 & 11 & 52 & 1 & 0 & 3 & 138 & 14,46 \\
\hline Mikse & 0 & 40 & 0 & 0 & 17 & 0 & 0 & 0 & 57 & 5,94 \\
\hline Taksa (Xhizje) & 0 & 1 & 0 & 0 & 0 & 0 & 0 & 0 & 1 & 0,1 \\
\hline Total & 178 & 277 & 18 & 69 & 251 & 27 & 118 & 21 & 959 & 100 \\
\hline
\end{tabular}

Sikurse shihet, përqindjen më të madhe të akteve penale e formojnë vrasjet $68,8 \%$, grabitjet $14,46 \%$ dhe plagosjet $8,4 \%$. 


\section{Albanon}

Revistë kulturore

\section{Grabitje}

Grabitjet mund të ishin të qëllimshme, në rastet kur grabitësit identifikoheshin, ose të paqëllimshme. Me këto të fundit nënkuptoheshin rastet kur pretendohej se bagëtia nuk ishte grabitur, por ajo kishte humbur dhe ishte gjetur nga personi, i cili të shumtën e rasteve ia shiste një pale të tretë që ta hiqte duarsh. Në rast se pronari i bagëtisë e zbulonte ku gjendej bagëtia që kishte humbur dhe arrinte të dëshmonte para gjyqit karakteristikat e saj (që tregonte se e njihte mirë) dhe pala që e zotëronte nuk arrinte të vërtetonte pronësinë e saj, atëherë kafsha i kthehej të zotit, ndërsa personi që e kishte gjetur dhe shitur kafshën, detyrohej t'i kthente personit që ia kishte shitur shumën me të cilën ia kishte shitur.

Në parim, preferohej kthimi në natyrë e armëve, objekteve apo kafshëve që ishin grabitur, mirëpo duke u pretenduar se ato mund të ishin konsumuar apo dëmtuar gjatë kësaj kohe, vlera e tyre konvertohej në para sipas vlerës së tregut dhe pajtimi arrihej kur paguhej shuma e përcaktuar.

\section{Plagosje}

Plagosjet ndaheshin në dy lloje, sipas shkallës së dëmtimit që kishin shkaktuar: në plagosje të lehta dhe plagosje të rënda (konsideroheshin plagosjet që shkaktonin dëme fizike të paripakurueshme; sakat). Pagesa e pajtimit për këto të dyja ishte më e rëndë, por më pak se 1250 groshë.

\section{Vrasje}

Sipas së drejtës osmane, që bazohej në të drejtën e sheriatit (ligji islamik), dënimi për vrasjen me paramendim ishte vetëm një; ekzekutimi i vrasësit. Ky dënim nuk ekzekutohet nga shteti vetëm në rastin kur pasardhësit e të vrarit pranojnë t’ia falin gjakun vrasësit.

Në rast se vrasja është bërë pa paramendim, vrasësi duhet t’i paguajë një shumë pasardhësve të së vrarit. Pikërisht bazuar në këtë kontekst ligjor, shteti osman për të zbutur efektet e gjakmarrjes në perandori në përgjithësi dhe në Shqipëri në veçanti, krijoi komisionet e pajtimit të gjaqeve që pajtonin palët me pëlqimin e të dy palëve dhe i pajisnin me dokumentin përkatës të pajtimit.

Nga regjistri i pajtimeve i viteve 1845-1846, mësojmë se shuma që duhej paguar për pajtimin e gjaqeve ishte përcaktuar me ferman të sulltanit dhe 
ishte 1250 groshë për person. Në rast se vrasësi kishte vrarë më shumë se një person nga një familje, ai duhej ta paguante këtë shumë për çdonjërin prej tyre. Mund të paguhej edhe më pak ose aspak, por kjo ndodhte kur dy palët pajtoheshin në këtë pikë, gjë që ndodhte shpesh kur vërtetohej se, ndërkohë pala e të vrarit mund të kishte vrarë apo plagosur rëndë një person nga familja e vrasësit dhe kjo e bënte përllogaritjen mes palëve nul.

Në rast se nuk identifikohej personi vrasës, përgjegjës për pagimin e vlerës së gjakmarrjes, ishin banorët e fshatit ku kishte ndodhur vrasja, të cilët mblidhnin mes tyre shumën dhe ia dorëzonin atë palës të së vrarit përmes kryeplakut të fshatit, që quhej myhtar për fshatrat myslimanë apo koxhabash, për fshatrat e krishtera.

Më poshtë jepet statistika e vrasjeve sipas kazave përkatëse.

\section{Kazaja e Beratit dhe nahijet e saj (Skrapar, Tomorricë, Mallakastër)}

Rastet kur vrasjet kanë ndodhur mes banorëve të të njëjtit fshat:

\begin{tabular}{|c|l|c|}
\hline $\begin{array}{r}\text { Numri } \\
\text { rendor }\end{array}$ & \multicolumn{1}{|c|}{ Fshati } & Raste \\
\hline 1. & Berat qytet & 2 \\
\hline 2. & Ballsh & 1 \\
\hline 3. & Banaj & 1 \\
\hline 4. & Bistrovica & 1 \\
\hline 5. & Bjeshova & 3 \\
\hline 6. & Çakran & 1 \\
\hline 7. & Çerven & 1 \\
\hline 8. & Çorogjaf & 1 \\
\hline 9. & Drenova & 1 \\
\hline 10. & Frakulla & 1 \\
\hline 11. & Goriçan & 1 \\
\hline 12. & Gorishova & 2 \\
\hline 13. & Gjerbes & 2 \\
\hline 14. & Goranj & 1 \\
\hline 15. & Hallambras & 1 \\
\hline 16. & Kamçisht & 1 \\
\hline 17. & Kafaraj & 3 \\
\hline 18. & Kalehna & 2 \\
\hline
\end{tabular}




\section{Albanon}

Revistë kulturore

\begin{tabular}{|c|c|c|}
\hline $\begin{array}{l}\text { Numri } \\
\text { rendor }\end{array}$ & Fshati & Raste \\
\hline 19. & Kapali & 1 \\
\hline 20. & Koresh & 1 \\
\hline 21. & Kostren & 2 \\
\hline 22. & Kozara & 1 \\
\hline 23. & Kuta & 1 \\
\hline 24. & Kremenar & 1 \\
\hline 25. & Kreshpan & 1 \\
\hline 26. & Kryet & 2 \\
\hline 27. & Kutalli & 2 \\
\hline 28. & Lapulec & 1 \\
\hline 29. & Lapardha & 1 \\
\hline 30. & Leshnja & 1 \\
\hline 31. & Levan plaka & 1 \\
\hline 32. & Lubesha & 3 \\
\hline 33. & Mapsh & 2 \\
\hline 34. & Mallakas & 1 \\
\hline 35. & Mbrakull & 1 \\
\hline 36. & Mollas & 1 \\
\hline 37. & Nivan & 2 \\
\hline 38. & Novan & 2 \\
\hline 39. & Novosela & 1 \\
\hline 40. & Osmanzeza & 1 \\
\hline 41. & Patos & 1 \\
\hline 42. & Peshtan & 3 \\
\hline 43. & Plashnik & 2 \\
\hline 44. & Ruzhdije & 1 \\
\hline 45. & Sfir & 2 \\
\hline 46. & Smuraj & 1 \\
\hline 47. & Strum & 1 \\
\hline 48. & Suk & 1 \\
\hline 49. & Terpan & 1 \\
\hline 50. & Velagosht & 1 \\
\hline 51. & Vidhishta & 1 \\
\hline 52. & Visoka & 1 \\
\hline \multirow[t]{2}{*}{53.} & Vreshtas & 3 \\
\hline & Total & 73 \\
\hline
\end{tabular}


Raste kur ngjarjet kanë ndodhur mes banorëve të fshatrave të ndryshme të kazasë së Beratit (përfshirë edhe nahijen e Skraparit):

\begin{tabular}{|c|c|c|}
\hline $\begin{array}{l}\text { Numri } \\
\text { rendor }\end{array}$ & Vrasësi & I vrari \\
\hline 1. & Aranitas & Gjerbes \\
\hline 2. & Baljadon & Leshna \\
\hline 3. & Balonjal & Bjeshova \\
\hline 4. & Barç & Polovina \\
\hline 5. & Berat qytet & Perhondi \\
\hline 6. & Berat qytet & Perisnak \\
\hline 7. & Buzmath & Vreshtas \\
\hline 8. & Çakran & Patos \\
\hline 9. & Çakran & Varibob \\
\hline 10. & Çiftlik i ri & Poshnja \\
\hline 11. & Çorogjaf & Regjistruesi e ka lënë bosh \\
\hline 12. & Dobrusha (Skrapar) & Sirakat \\
\hline 13. & Drenova & Patos \\
\hline 14. & Driza & Çerven \\
\hline 15. & Fratar & Çorush \\
\hline 16. & Grabinço & Andrejina \\
\hline 17. & Graçan & Hallambras \\
\hline 18. & Gjerbes & Sadoviça \\
\hline 19. & Kafaraj & Çerven \\
\hline 20. & Kalem & Çorogjaf \\
\hline 21. & Kostren & Leshna \\
\hline 22. & Kozara & Imshta \\
\hline 23. & Krushova & Lapulec \\
\hline 24. & Lapardha & Berat qyteti \\
\hline 25. & Lapardha & Slanica \\
\hline 26. & Lavdan & Bubza (Bubes) \\
\hline 27. & Leshnica (Skrapar) & Duhanas \\
\hline 28. & Lumas & Hajdarbejan \\
\hline 29. & Lumas & Hajdarbejan \\
\hline 30. & Lumas & Velagosht \\
\hline 31. & Malinat & Vokopola \\
\hline
\end{tabular}




\section{Albanon}

Revistë kulturore

\begin{tabular}{|c|c|c|}
\hline $\begin{array}{l}\text { Numri } \\
\text { rendor }\end{array}$ & Vrasësi & I vrari \\
\hline 32. & Marina & Barbullonj \\
\hline 33. & Marina & Kuman \\
\hline 34. & Mollas & Kozara \\
\hline 35. & Panahor & Graçan \\
\hline 36. & Panahor & Kalehna \\
\hline 37. & Perhondi & Kuçova \\
\hline 38. & Perisnak & Kostren \\
\hline 39. & Plashnik & Goranj \\
\hline 40. & Polovina & Sulova \\
\hline 41 & Poshna & Morava \\
\hline 42. & Rerza & Luar \\
\hline 43. & Reth & Kozara \\
\hline 44. & Reth tapi & Havalijas (Avaleas) \\
\hline 45. & Reth tapi & Poshnja \\
\hline 46. & Selishta & Backa \\
\hline 47. & Selishta & Gjonça \\
\hline 48. & Simuranj & Lumas \\
\hline 49. & Sheq & Çorush \\
\hline 50. & Sheq & Kreshpan \\
\hline 51. & Shemberdhenj & Kryet \\
\hline 52. & Teman & Vokopola \\
\hline 53. & Therepel (Skrapar) & Ballguras \\
\hline 54. & Velabisht & Sinjar \\
\hline 55. & Regjistruesi e ka lënë bosh & Buzmath \\
\hline 56. & Regjistruesi e ka lënë bosh & Buzmath \\
\hline 57. & Regjistruesi e ka lënë bosh & Kasnica \\
\hline 58. & Regjistruesi e ka lënë bosh & Kuta \\
\hline 59. & Regjistruesi e ka lënë bosh & Kozara \\
\hline 60. & Regjistruesi e ka lënë bosh & Koresh \\
\hline 61. & Regjistruesi e ka lënë bosh & Panahor \\
\hline 62. & Regjistruesi e ka lënë bosh & Pirza \\
\hline 63. & Regjistruesi e ka lënë bosh & Plashnik \\
\hline 64. & Regjistruesi e ka lënë bosh & Velmisht \\
\hline
\end{tabular}




\section{Myzeqeja (nahije)}

Vrasje, mes banorëve të të njëjtit fshat:

\begin{tabular}{|c|l|c|}
\hline $\begin{array}{c}\text { Numri } \\
\text { rendor }\end{array}$ & Fshati & Raste \\
\hline 1. & Ardenica & 1 \\
\hline 2. & Barbullonja & 1 \\
\hline 3. & Hisan & 1 \\
\hline 4. & Imshta & 1 \\
\hline 5. & Kosova & 1 \\
\hline 6. & Lushnja & 2 \\
\hline & Total & 7 \\
\hline
\end{tabular}

Vrasje mes banorëve të fshatrave të ndryshme të Mallakastrës:

\begin{tabular}{|c|l|l|c|}
\hline $\begin{array}{c}\text { Numri } \\
\text { rendor }\end{array}$ & \multicolumn{1}{|c|}{ Vrasësi } & \multicolumn{1}{|c|}{ I vrari } & Raste \\
\hline 1. & I paverifikueshëm & Kryet & 1 \\
\hline 2. & Bishqem & Regjistruesi e ka lënë bosh & 1 \\
\hline 3. & Gjokalli & Regjistruesi e ka lënë bosh & 1 \\
\hline 4. & Korita & Lushnja & 1 \\
\hline 5. & Kosova & Regjistruesi e ka lënë bosh & 1 \\
\hline 6. & Kosova & Regjistruesi e ka lënë bosh & 1 \\
\hline & Total & & 6 \\
\hline
\end{tabular}

\section{Skrapar (nahije)}

Vrasje, mes banorëve të të njëjtit fshat:

\begin{tabular}{|c|l|l|}
\hline $\begin{array}{c}\text { Numri } \\
\text { rendor }\end{array}$ & \multicolumn{1}{|c|}{ Fshati } & Raste \\
\hline 1. & Backa & 2 \\
\hline 2. & Belzençka & 1 \\
\hline 3. & Dobrusha & 1 \\
\hline 4. & Gjergjova & 1 \\
\hline 5. & Kallanas (Kalanjas) & 1 \\
\hline 6. & Kapinova & 1 \\
\hline 7. & Kopricka & 1 \\
\hline
\end{tabular}




\section{Albanon}

Revistë kulturore

\begin{tabular}{|c|l|c|}
\hline $\begin{array}{c}\text { Numri } \\
\text { rendor }\end{array}$ & \multicolumn{1}{|c|}{ Fshati } & Raste \\
\hline 8. & Leshna & 1 \\
\hline 9. & Mollas & 2 \\
\hline 10. & Munushtir & 2 \\
\hline 11. & Muzhaka & 1 \\
\hline 12. & Osoja & 2 \\
\hline 13. & Paraspor & 1 \\
\hline 14. & Polena & 1 \\
\hline 15. & Potom & 1 \\
\hline 16. & Rahovica & 2 \\
\hline 17. & Sevran & 2 \\
\hline 18. & I paverifikueshëm & 2 \\
\hline 19. & Spathar & 4 \\
\hline 20. & Staravecka & 1 \\
\hline 21. & Therepel & 2 \\
\hline 22. & Vendresha & 2 \\
\hline 23. & Vokopola & 2 \\
\hline 24. & Vreshta & 1 \\
\hline 25. & Zabarzan & 1 \\
\hline 26. & Zgrovbonja (Zgërbonja) & 1 \\
\hline & Total & 38 \\
\hline & & \\
\hline
\end{tabular}

Vrasje, mes banorëve të fshatrave të ndryshme:

\begin{tabular}{|c|l|l|c|}
\hline $\begin{array}{c}\text { Numri } \\
\text { rendor }\end{array}$ & \multicolumn{1}{|c|}{ Vrasës } & \multicolumn{1}{|c|}{ I vrari } & Raste \\
\hline 1. & Çerenishta & Kalasa & 1 \\
\hline 2. & Çerenishta & Koprencka & 1 \\
\hline 3. & Grat & Vokopola & 1 \\
\hline 4. & Lubona & Osoja & 1 \\
\hline 5. & I paverifikueshëm & Çepan & 1 \\
\hline 6. & Plashnik & Blezencka & 1 \\
\hline 7. & I paverifikueshëm & Skrapar & 1 \\
\hline 8. & Spathar & Vendresha & 1 \\
\hline 9. & Visocka & I paverifikueshëm & 1 \\
\hline 10. & I paverifikueshëm & Paraspor & 1 \\
\hline
\end{tabular}




\begin{tabular}{|c|l|l|c|}
\hline $\begin{array}{c}\text { Numri } \\
\text { rendor }\end{array}$ & \multicolumn{1}{|c|}{ Vrasës } & \multicolumn{1}{|c|}{ I vrari } & Raste \\
\hline 11. & Vlosha & Backa & 1 \\
\hline 12. & I paverifikueshëm & Gjergjova & 1 \\
\hline 13. & Zhezha & Sevran & 1 \\
\hline 14. & Zhezha & Veleshna & 1 \\
\hline Total & & & 14 \\
\hline
\end{tabular}

\section{Nahija e Tomorricës}

Vrasje, mes banorëve të të njëjtit fshat:

\begin{tabular}{|c|l|c|}
\hline $\begin{array}{c}\text { Numri } \\
\text { rendor }\end{array}$ & \multicolumn{1}{|c|}{ Fshati } & Raste \\
\hline 1. & Peca & 1 \\
\hline 2. & Dardha & 1 \\
\hline 3. & Ermen & 1 \\
\hline 4. & Kopricka & 1 \\
\hline 5. & Maleshova & 1 \\
\hline 6. & Shëmberdhenj & 2 \\
\hline 7. & Verzhezhda & 1 \\
\hline 8. & Vidhan & 1 \\
\hline 9. & I paverifikueshëm & 1 \\
\hline Total & & 10 \\
\hline
\end{tabular}

Vrasje, mes banorëve të fshatrave të ndryshme:

\begin{tabular}{|c|l|l|c|}
\hline $\begin{array}{c}\text { Numri } \\
\text { rendor }\end{array}$ & \multicolumn{1}{|c|}{ Vrasësi } & \multicolumn{1}{c|}{ I vrari } & Raste \\
\hline 1. & Ermen & Shëmberdhenj & 1 \\
\hline 2. & Gjergjova & Gramsh & 1 \\
\hline 3. & Kerpica & Staravecka & 1 \\
\hline 4. & Koxhan & Qafa & 1 \\
\hline 5. & Leshnja & Tomorrica & 1 \\
\hline 6. & Qafa & Staravecka & 1 \\
\hline 7. & Shëmberdhenj & Kerpica & 1 \\
\hline 8. & Regjistruesi e ka lënë bosh & Shëmberdhenj & 2 \\
\hline Total & & & 8 \\
\hline
\end{tabular}




\section{Albanon}

Revistë kulturore

\section{Kazaja e Vlorës}

Rastet, kur vrasjet kanë ndodhur brenda të njëjtit fshat:

\begin{tabular}{|l|c|}
\hline \multicolumn{1}{|c|}{ Fshati } & Rastet \\
\hline Armen & 1 \\
\hline Brataj & 2 \\
\hline Dracovica & 2 \\
\hline Dukat & 5 \\
\hline Gorishta & 1 \\
\hline Gjonm & 1 \\
\hline Hoshtima & 1 \\
\hline Hysovjerdha & 1 \\
\hline Kanina & 1 \\
\hline Kudhs & 12 \\
\hline Malkaj & 1 \\
\hline Qishbardha & 1 \\
\hline Roms & 4 \\
\hline Smokthina & 13 \\
\hline Tragjas & 3 \\
\hline Vajza & 1 \\
\hline Vlora qyteti & 1 \\
\hline Vodiça & 12 \\
\hline Total & \\
\hline
\end{tabular}

Rastet, kur vrasjet kanë ndodhur mes banorëve të fshatrave të ndryshme, por që varen nga kazaja e Vlorës:

\begin{tabular}{|c|l|l|c|}
\hline $\begin{array}{c}\text { Numri } \\
\text { rendor }\end{array}$ & \multicolumn{1}{|c|}{ Vrasësi } & I vrari & Raste \\
\hline 1. & Amoniça & Kudhs & 1 \\
\hline 2. & Çiflig & Mekat & 1 \\
\hline 3. & Dracovica & Peshkopi & 1 \\
\hline 4. & Dukat & Tragjas & 1 \\
\hline 5. & Dukat & Vlora qyteti & 1 \\
\hline 6. & Goriça & Llakatund & 1 \\
\hline 7. & Gumenica & Tragjas & 1 \\
\hline 8. & Gumenica & Vajza & 1 \\
\hline
\end{tabular}




\begin{tabular}{|c|c|c|c|}
\hline $\begin{array}{l}\text { Numri } \\
\text { rendor }\end{array}$ & Vrasësi & I vrari & Raste \\
\hline 9. & Gjonm & Brataj & 1 \\
\hline 10. & Hoshtima & Tragjas & 1 \\
\hline 11. & Vermik & Smokthina & 1 \\
\hline 12. & Kaçulaj (Koculaj) & Vranishta & 2 \\
\hline 13. & Amonica & Vajza & 1 \\
\hline 14. & Kanina & Smokthina & 1 \\
\hline 15. & Korishta & Brataj & 1 \\
\hline 16. & Korishta & Kudhs & 2 \\
\hline 17. & Krasnjar & Roms & 1 \\
\hline 18. & Kudhs & Amonica & 1 \\
\hline 19. & Kudhs & Vermik & 1 \\
\hline 20. & Kudhs & Korishta & 3 \\
\hline 21. & Kudhs & Lepenica & 1 \\
\hline 22. & Kudhs & Smokthina & 1 \\
\hline 23. & Lepenica & Brataj & 1 \\
\hline 24. & Mekat & Korishta & 1 \\
\hline 25. & Mekat & Yçkardesh (Trevllazën) & 1 \\
\hline 26. & Penkova & Smokthina & 1 \\
\hline 27. & Radhima & Kanina & 1 \\
\hline 28. & Smokthina & Kanina & 1 \\
\hline 29. & Smokthina & Tragjas & 1 \\
\hline 30. & Smokthina & Tërbaç & 1 \\
\hline 31. & Smokthina & Vajza & 1 \\
\hline 32. & Smokthina & Velça & 1 \\
\hline 33. & Tragjas & Dukat & 1 \\
\hline 34. & Tragjas & Gumenica & 1 \\
\hline 35. & Tragjas & Palasa & 1 \\
\hline 36. & Tragjas & Radhima & 1 \\
\hline 37. & Tërbaç & Smokthina & 1 \\
\hline 38. & Tërbaç & Vajza & 1 \\
\hline 39. & Tërbaç & Vlora kaza & 1 \\
\hline 40. & Trebleva & Andriçani & 1 \\
\hline 41. & Treblova & Kanina & 1 \\
\hline
\end{tabular}




\section{Albanon}

Revistë kulturore

\begin{tabular}{|c|l|l|c|}
\hline $\begin{array}{c}\text { Numri } \\
\text { rendor }\end{array}$ & \multicolumn{1}{|c|}{ Vrasësi } & \multicolumn{1}{|c|}{ I vrari } & Raste \\
\hline 42. & Velça & Brataj & 1 \\
\hline 43. & Velça & Lepeniça & 2 \\
\hline 44. & Vranishta & Tërbaç & 2 \\
\hline 45. & Vlora kaza & Kudhs & 2 \\
\hline 46. & I paverifikueshëm & Radhima & 1 \\
\hline & Total & & 54 \\
\hline
\end{tabular}

Rastet, kur vrasjet kanë ndodhur mes banorëve të fshatrave të kazave të ndryshme Vlorë, Tepelenë dhe Delvinë:

\begin{tabular}{|l|l|c|}
\hline \multicolumn{1}{|c|}{ Vrasësi } & \multicolumn{1}{c|}{ I vrari } & Raste \\
\hline Brataj (Vlora) & Lops (Tepelena) & 1 \\
\hline Kanina (Vlora) & Beçisht (Tepelena) & 1 \\
\hline Kanina (Vlora) & Vasjar (Tepelena) & 1 \\
\hline Krasnjar (Vlora) & Sinan Mehmet (Tepelena) & 1 \\
\hline Llakatund (Vlora) & Kallarat (Delvina) & 1 \\
\hline Total & & 5 \\
\hline
\end{tabular}

\section{Kazaja e Tepelenës}

Rastet, kur vrasjet kanë ndodhur mes banorëve të të njëjtit fshat:

\begin{tabular}{|c|l|c|}
\hline $\begin{array}{c}\text { Numri } \\
\text { rendor }\end{array}$ & \multicolumn{1}{|c|}{ Fshat } & Raste \\
\hline 1. & Allja & 1 \\
\hline 2. & Arrez & 1 \\
\hline 3. & Ball & 1 \\
\hline 4. & Bença & 3 \\
\hline 5. & Bobs & 3 \\
\hline 6. & Buz & 4 \\
\hline 7. & Çorogun & 1 \\
\hline 8. & Dams & 2 \\
\hline 9. & Doreza & 5 \\
\hline 10. & Dragot & 2 \\
\hline 11. & I paverifikueshëm & 2 \\
\hline 12. & Hoshtova & \\
\hline
\end{tabular}




\begin{tabular}{|c|l|c|}
\hline $\begin{array}{c}\text { Numri } \\
\text { rendor }\end{array}$ & \multicolumn{1}{|c|}{ Fshat } & Raste \\
\hline 13. & Iljar & 1 \\
\hline 14. & Këlcyra & 1 \\
\hline 15. & Koshtan & 2 \\
\hline 16. & Krahas & 4 \\
\hline 17. & Leskoveç & 2 \\
\hline 18. & Luftinja & 2 \\
\hline 19. & Marina & 1 \\
\hline 20. & Mazhan & 1 \\
\hline 21. & Memalija & 1 \\
\hline 22. & Matohasaj, Matohasanaj & 2 \\
\hline 23. & Mazhan & 1 \\
\hline 24. & I paverifikueshëm & 1 \\
\hline 25. & Panarit & 3 \\
\hline 26. & Pavar & 1 \\
\hline 27. & Podgoran & 1 \\
\hline 28. & Salari & 6 \\
\hline 29. & Sinanaj & 1 \\
\hline 30. & Tepelena qytet & 1 \\
\hline 31. & Topojan & 1 \\
\hline 32. & Turan & 1 \\
\hline 33. & Vinokash & 1 \\
\hline 34. & Zemblan & \\
\hline 35. & Zhapokika & Total \\
\hline & & 1 \\
\hline
\end{tabular}

Rastet, kur vrasjet janë kryer mes banorësh të fshatrave të ndryshme të kazasë së Tepelenës:

\begin{tabular}{|c|l|l|c|}
\hline $\begin{array}{c}\text { Numri } \\
\text { rendor }\end{array}$ & \multicolumn{1}{|c|}{ Vrasësi } & \multicolumn{1}{|c|}{ I vrari } & Raste \\
\hline 1. & Areza & Psar & 1 \\
\hline 2. & Areza & Zhapokika & 1 \\
\hline 3. & Ball & Psar & 1 \\
\hline 4. & Bença & Salari & 1 \\
\hline 5. & Btosh & Mazhan & 1 \\
\hline
\end{tabular}




\section{Albanon}

Revistë kulturore

\begin{tabular}{|c|l|l|c|}
\hline $\begin{array}{c}\text { Numri } \\
\text { rendor }\end{array}$ & Vrasësi & \multicolumn{1}{|c|}{ I vrari } & Raste \\
\hline 6. & Bubs & Psar & 1 \\
\hline 7. & Buz & Mazhan & 1 \\
\hline 8. & Buz & Pavar & 1 \\
\hline 9. & Dams & Mariçan & 1 \\
\hline 10. & Doreza & Kalivaç & 2 \\
\hline 11. & Doreza & Zemblan & 1 \\
\hline 12. & Doreza & Sinanaj & 1 \\
\hline 13. & Doreza & Sinan Mehmed & 1 \\
\hline 14. & Doreza & Toç & 1 \\
\hline 15. & Doreza & Topi & 1 \\
\hline 16. & Doreza & Turan & 1 \\
\hline 17. & Dragot & Krahes & 1 \\
\hline 18. & Dragot & Mexhdgoran & 1 \\
\hline 19. & Dukaj & Tepelen qyteti & 1 \\
\hline 20. & Dukaj & Turan & 1 \\
\hline 21. & Dukaj & Varfaj & 1 \\
\hline 22. & Dhivra & Zhepova & 1 \\
\hline 23. & I paverifikueshëm & Psar & 1 \\
\hline 24. & Izvor & Luftinja & 1 \\
\hline 25. & Kajça & Btosh & 1 \\
\hline 26. & Kajça & Psar & 1 \\
\hline 27. & Kalivaç & Koshtoj & 1 \\
\hline 28. & Këlcyra & Mariçan & 1 \\
\hline 29. & Këlcyra & Podgoran & 1 \\
\hline 30. & Kashisht & Vasjar & 1 \\
\hline 31. & Krahas & Toç & 1 \\
\hline 32. & Labova & Hormova & 1 \\
\hline 33. & Leskoviç & Mariçan & 1 \\
\hline 34. & Levan & Mazhan & 1 \\
\hline 35. & Luzat & Bença & 1 \\
\hline 36. & Lezat & Lezat & 1 \\
\hline 37. & Luftinja & 1 \\
\hline 38. & & 1 \\
\hline & & Mecoran & 1 \\
\hline
\end{tabular}




\begin{tabular}{|c|c|c|c|}
\hline $\begin{array}{l}\text { Numri } \\
\text { rendor }\end{array}$ & Vrasësi & I vrari & Raste \\
\hline 39. & Luftinja & Izvor & 1 \\
\hline 40. & Luftinja, Zhapokika & Lukth & 1 \\
\hline 41. & Mariçan & Martallos & 1 \\
\hline 42. & Mariçan & Zhapokika & 1 \\
\hline 43. & Martallos & Kalis & 1 \\
\hline 44. & Martalos & Leskoviç & 1 \\
\hline 45. & Martalos & Veliqot & 2 \\
\hline 46. & Mazhan & Bubs & 1 \\
\hline 47. & Mecdgoran & Dams & 1 \\
\hline 48. & Mecdgoran & Salari & 1 \\
\hline 49. & Memalija & Dams & 1 \\
\hline 50. & Panarit & Buz & 1 \\
\hline 51. & Pavar & Vinokash & 1 \\
\hline 52. & Progonat & Këlcyra & 1 \\
\hline 53. & Qesarat & Dams & 2 \\
\hline 54. & Qesarat & Zemblan & 1 \\
\hline 55. & Sinan mehmed & Doreza & 1 \\
\hline 56. & Sinan Mehmed & Dukaj & 1 \\
\hline 57. & Sinan Mehmed & Martalos & 1 \\
\hline 58. & Sinan & Salari & 1 \\
\hline 59. & Shalis & Buz & 1 \\
\hline 60. & Shalis & Martallos & 1 \\
\hline 61. & Tepelena kaza & Memaliaj & 1 \\
\hline 62. & Toç & Doreza & 1 \\
\hline 63. & Toç & Kalivaç & 1 \\
\hline 64. & Tolat & Panarit & 1 \\
\hline 65. & Turan & Dams & 1 \\
\hline 66. & Turan & Dukaj & 1 \\
\hline 67. & Turan & Veliqot & 1 \\
\hline 68. & I paverifikueshëm & Martallos & 1 \\
\hline 69. & Veliqot & Salari & 1 \\
\hline 70. & Zemblan & Doreza & 1 \\
\hline 71. & Zemblan & Martallos & 1 \\
\hline
\end{tabular}




\section{Albanon}

\section{Revistë kulturore}

\begin{tabular}{|c|l|l|c|}
\hline $\begin{array}{c}\text { Numri } \\
\text { rendor }\end{array}$ & \multicolumn{1}{|c|}{ Vrasësi } & \multicolumn{1}{c|}{ I vrari } & Raste \\
\hline 72. & Zemblan & Matohasanaj & 2 \\
\hline 73. & Zemblan & Salari & 3 \\
\hline 74. & Zhapokika & Mariçan & 1 \\
\hline 75. & Zhapokika & Martallos & 1 \\
\hline 76. & Zhapokika & Vasjar & 1 \\
\hline 77. & Regjistruesi e ka lënë bosh & Martallos & 1 \\
\hline & Total & & 83 \\
\hline
\end{tabular}

Raste vrasjeve dhe grabitjeve, që kanë ndodhur mes banorëve të fshatrave të kazasë së Tepelenës me banorë të fshatrave të kazave të tjera:

\begin{tabular}{|c|l|l|c|}
\hline $\begin{array}{c}\text { Numri } \\
\text { rendor }\end{array}$ & \multicolumn{1}{|c|}{ Akti penal/Fshati } & \multicolumn{1}{|c|}{ I vrari } & Raste \\
\hline 1. & Grabitje/Beçisht & Trebicka (Korça) & 1 \\
\hline 2. & Grabitje/Bença & I paverifikueshëm & 1 \\
\hline 3. & Vrasje/Dams & I paverifikueshëm & 1 \\
\hline 4. & Grabitje/Dukaj & I paverifikueshëm & 1 \\
\hline 5. & Grabitje/Erind & Seliçka & 1 \\
\hline 6. & Grabitje/Kashisht & Përmet & 1 \\
\hline 7. & Vrasje/Mazhar & Sopik (Pogon) & 1 \\
\hline 8. & Vrasje/Panarit & Trebicka, Treska & 1 \\
\hline 9. & Grabitje/I paverifikueshëm & Seleçka (Pogon) & 1 \\
\hline 10. & Vrasje/Seleçka & Çepan (Skrapar) & 1 \\
\hline 11. & Grabitje/I paverifikueshëm & Sopik (Pogon) & 1 \\
\hline 12. & Grabitje/Tepelena qytet & Frakull (Berat) & 1 \\
\hline 13. & Grabitje/Tepelena qytet & Kremenar (Berat) & 1 \\
\hline 14. & Grabitje/Tepelena karyeleri & Elbasan qyteti & 1 \\
\hline 15. & Grabitje/Turan & Protopapa & 1 \\
\hline 16. & Grabitje/Vasjar (tepelena) & Odriçan (Skrapar) & 1 \\
\hline 17. & Vrasje/Vinokash (Tepelena) & Therepel (Skrapar) & 1 \\
\hline
\end{tabular}




\section{Kazaja e Konicës}

Vrasje mes banorëve të të njëjtit fshat:

\begin{tabular}{|c|l|c|}
\hline $\begin{array}{c}\text { Numri } \\
\text { rendor }\end{array}$ & \multicolumn{1}{|c|}{ Fshati } & Raste \\
\hline 1. & Aguriçan & 2 \\
\hline 2. & Leshkoniq & 1 \\
\hline 3. & Seran & 4 \\
\hline Total & & 7 \\
\hline
\end{tabular}

Vrasje mes banorëve të fshatrave të ndryshme

\begin{tabular}{|c|l|l|c|}
\hline $\begin{array}{c}\text { Numër } \\
\text { rendor }\end{array}$ & \multicolumn{1}{|c|}{ Vrasësi } & \multicolumn{1}{c|}{ I vrari } & Raste \\
\hline 1. & Agoriçan & Glina & 1 \\
\hline 2. & Glina & Agoriçan & 2 \\
\hline 3. & Glina & Teqeja e Turanit & 1 \\
\hline 4. & Glina & Seran & 1 \\
\hline 5. & I paverifikueshëm & Seran & 1 \\
\hline 6. & Seran & Glina & 1 \\
\hline 7. & Seran & Leskoviq & 1 \\
\hline 8. & Tepelena kazası & Trebicka, Treska, Panarit & 1 \\
\hline 9. & Regjistruesi e ka lënë bosh & Agoriçan & 1 \\
\hline 10. & Regjistruesi e ka lënë bosh & Seran & 1 \\
\hline Total & & & 11 \\
\hline
\end{tabular}

\section{Kazaja e Delvinës}

Vrasje mes banorëve të të njëjtit fshat:

\begin{tabular}{|c|l|c|}
\hline $\begin{array}{c}\text { Numër } \\
\text { rendor }\end{array}$ & \multicolumn{1}{|c|}{ Fshat } & Raste \\
\hline 1. & Qyteti Delvina & 4 \\
\hline 2. & Bolena & 1 \\
\hline 3. & Borsh & 14 \\
\hline 4. & Ftera & 1 \\
\hline 5. & Golem & 1 \\
\hline 6. & Gusmar & 2 \\
\hline
\end{tabular}




\section{Albanon}

Revistë kulturore

\begin{tabular}{|c|l|c|}
\hline $\begin{array}{c}\text { Numër } \\
\text { rendor }\end{array}$ & \multicolumn{1}{|c|}{ Fshat } & Raste \\
\hline 7. & Himara & 1 \\
\hline 8. & Kardhiq & 3 \\
\hline 9. & Kraznea & 1 \\
\hline 10. & Kolonja & 1 \\
\hline 11. & Kuç & 2 \\
\hline 12. & Mashkullor & 1 \\
\hline 13. & Nivica & 2 \\
\hline 14. & Qeparo & 1 \\
\hline 15. & Palasa & 1 \\
\hline 16. & Pandelimon & 1 \\
\hline 17. & Piluri & 1 \\
\hline 18. & Picar & 2 \\
\hline 19. & Pirasa & 2 \\
\hline 20. & Progonat & 1 \\
\hline 21. & Qeparo & 3 \\
\hline 22. & Zhulat & 3 \\
\hline 23. & I paverifikueshëm & 1 \\
\hline Total & & $\mathbf{5 0}$ \\
\hline
\end{tabular}

Vrasje mes banorëve të fshatrave të ndryshme të kazasë së Delvinës:

\begin{tabular}{|c|l|l|c|}
\hline $\begin{array}{c}\text { Numër } \\
\text { rendor }\end{array}$ & \multicolumn{1}{|c|}{ Vrasësi } & I vrari & Raste \\
\hline 1. & Borsh & Tatzat & 3 \\
\hline 2. & Borsh & Zhulat & 2 \\
\hline 3. & Bolena & Nivica & 4 \\
\hline 4. & Delvina qytet & Brajlat & 1 \\
\hline 5. & Delvina qytet & Golem & 1 \\
\hline 6. & Delvina qytet & Nivica & 1 \\
\hline 7. & Delvina qytet & Zhulat & 1 \\
\hline 8. & Dhermi & Koshtan & 1 \\
\hline 9. & Dhikuri & Goriça & 1 \\
\hline 10. & Dhermi & Vuno & 1 \\
\hline 11. & Dhrovjan & Qesarat & 1 \\
\hline 12. & Ftera & Xhuraj & 1 \\
\hline & & & \\
\hline
\end{tabular}




\begin{tabular}{|c|c|c|c|}
\hline $\begin{array}{l}\text { Numër } \\
\text { rendor }\end{array}$ & Vrasësi & I vrari & Raste \\
\hline 13. & Ftera & Zhulat & 1 \\
\hline 14. & Golem & Borsh & 1 \\
\hline 15. & Golem & Ftera & 2 \\
\hline 16. & Golem & Kuç & 1 \\
\hline 17. & Golem & Sirakat & 1 \\
\hline 18. & Golem & Shullan & 1 \\
\hline 19. & Golem & Zhulat & 1 \\
\hline 20. & Goriça & I paverifikueshëm & 1 \\
\hline 21. & Goriça & Progonat & 1 \\
\hline 22. & Gjinorijo & Nivica & 1 \\
\hline 23. & Himara & Kuç & 1 \\
\hline 24. & Hoshtova & Progonat & 1 \\
\hline 25. & Kara Ali bej & Qeparo & 1 \\
\hline 26. & Kuç & Bunavija & 1 \\
\hline 27. & Kuç & Hormova & 1 \\
\hline 28. & Kuç & Kalladan & 1 \\
\hline 29. & Kuç & Xhuraj & 2 \\
\hline 30. & Kuç & Borsh & 1 \\
\hline 31. & Kuç & Nivica & 1 \\
\hline 32. & Kuç & Pandelimo & 1 \\
\hline 33. & Lazat & Golem & 1 \\
\hline 34. & Lazat & Pandelimon & 1 \\
\hline 35. & Lekdush & Koç & 1 \\
\hline 36. & Lekdush & Novosela & 1 \\
\hline 37. & Lekdush & Picar & 1 \\
\hline 38. & Lekdush & Progonat & 1 \\
\hline 39. & Leshnica & Golem & 2 \\
\hline 40. & Mashkullor & Kardhiq & 1 \\
\hline 41. & Nivica & Delvina qytet & 1 \\
\hline 42. & Nivica & Golem & 1 \\
\hline 43. & Nivica & Mile & 1 \\
\hline 44. & Nivica & Polena & 4 \\
\hline 45. & Nivica & Zhulat & 1 \\
\hline 46. & Palavli & Golem & 1 \\
\hline 47. & Piqeras & Qeparo & 1 \\
\hline
\end{tabular}




\section{Albanon}

Revistë kulturore

\begin{tabular}{|c|c|c|c|}
\hline $\begin{array}{l}\text { Numër } \\
\text { rendor }\end{array}$ & Vrasësi & I vrari & Raste \\
\hline 48. & Polena & Nivica & 1 \\
\hline 49. & Polena & Regjistruesi e ka lënë bosh & 1 \\
\hline 50. & Progonat & I paverifikueshëm & 1 \\
\hline 51. & Progonat & Frashar (Permedi) & 1 \\
\hline 52. & Progonat & Golem & 1 \\
\hline 53. & Progonat & Hundçova & 1 \\
\hline 54. & Progonat & Lekdush & 1 \\
\hline 55. & Progonat & Therri & 1 \\
\hline 56. & Progonat & Veçik & 1 \\
\hline 57. & Progonat & Zhulat & 3 \\
\hline 58. & Rexhima & Minga & 1 \\
\hline 59. & Qeparo & Piqeras & 1 \\
\hline 60. & Qeparo & Pirasa & 1 \\
\hline 61. & Senica & Nivica & 1 \\
\hline 62. & Sirakat & Golem & 1 \\
\hline 63. & Sirakat & Nivica & 1 \\
\hline 64. & Sopik, Golem, Nivica & Leshnica & 1 \\
\hline 65. & Tatzat & Borsh & 1 \\
\hline 66. & Tatzat & Piqeras & 1 \\
\hline 67. & Vergo & Brajlat & 1 \\
\hline 68. & Vuno & Himara & 1 \\
\hline 69. & Vuno & Koç & 1 \\
\hline 70. & Xhikagol & Borsh & 1 \\
\hline 71. & Xhuraj & Ftera & 1 \\
\hline 72. & Xhuraj & Koç & 2 \\
\hline 73. & Zhulat & Botoj & 1 \\
\hline 74. & Zhulat & Borsh & 3 \\
\hline 75. & Zhulat & Delvine qytet & 1 \\
\hline 76. & Zhulat & Golem & 2 \\
\hline 77. & Zhulat & Ftera & 1 \\
\hline 78. & Zhulat & Mashkullor & 2 \\
\hline 79. & Zhulat & Nivica & 1 \\
\hline 80. & Zhulat & Progonat & 1 \\
\hline 81. & Zhulat & Tatzat & 1 \\
\hline 82. & Zhulat & Dhrovjan & 1 \\
\hline
\end{tabular}




\begin{tabular}{|c|l|l|c|}
\hline $\begin{array}{c}\text { Numër } \\
\text { rendor }\end{array}$ & \multicolumn{1}{|c|}{ Vrasësi } & \multicolumn{1}{c|}{ I vrari } & Raste \\
\hline 83. & Xarra & Lekdush & 1 \\
\hline 84. & Regjistruesi e ka lënë bosh & Borsh & 1 \\
\hline 85. & Regjistruesi e ka lënë bosh & Çorat & 1 \\
\hline 86. & Regjistruesi e ka lënë bosh & Kalasa & 1 \\
\hline 87. & Regjistruesi e ka lënë bosh & Kallojani & 1 \\
\hline 88. & Regjistruesi e ka lënë bosh & Kardhiq & 2 \\
\hline 89. & Regjistruesi e ka lënë bosh & Nivica & 1 \\
\hline 90. & Regjistruesi e ka lënë bosh & Piluri & 1 \\
\hline 91. & Regjistruesi e ka lënë bosh & Qeparo & 1 \\
\hline 92. & I paverifikueshëm & Dolan & 1 \\
\hline 93. & I paverifikueshëm & Qeparo & 1 \\
\hline & Total & & 113 \\
\hline
\end{tabular}

Në regjistër janë regjistruar edhe raste grabitjesh dhe vrasjesh mes banorëve të fshatrave të Delvinës me banorë të fshatrave të kazave të ndryshme, më konkretisht me Janinën 6 grabitje, me Filatin 8 grabitje dhe 1 vrasje, me Gjirokastrën 13 grabitje dhe 1 vrasje, me Tepelenën 3 grabitje dhe 1 vrasje, me Konicën 1 grabitje dhe me Pogonin 5 grabitje dhe 1 huamarrje.

Për të pasur një ide mbi procesverbalin e pajtimit të gjaqeve që hartohej, po japim një tekt të përkthyer:

Abdurrahmani, nga fshati Koculaj, vrasësi $i$ Çelos birit të Çaushit, birit të Abdullahut, nga fshati Vranishtë e kazasë së Vlorës, i vrarë sot e gjashtë vjet më parë, u paraqit para giyqit të sheriatit përballë Myhtar Shametit nga fshati Vranishtë, përfaqësuesit ligjor të Ymykylthum bija e Ademit biri Muratit, e veja e të ndjerit të sipërpërmendur, bazuar në aktin legjitim të përfaqësimit, si dhe përballë kryepleqve dhe farefisit të aférm të së ndjerit dhe pasi palët u pajtuan mes tyre përpara gjyqit, me kusht që sot e tutje mos të kenë më asnjë mëtim në lidhje me zakonin e mbrapshtë dhe të dëmshëm të gjakmarrjes, $u$ krye edhe pagesa e vlerës së pajtimit të gjakmarrjes në shumën 1250 groshë, për të cilën palët u pajisën edhe me shkresën e vulosur nga imami dhe pleqësia e fshatit. $U$ parashtrohet ky procesverbal që t’u vëmë në dijeni për realitetin e këtij fakti, urdhri dhe fermani i takojnë të zotit të çështjes, më datë 15 dhjetor 1845. (BOA, BEO, Ayn.d, No. 1716, fl. 2/2) 